\title{
THE EFFLUENT TREATMENT TECHNOLOGIES AND COST ANALYSIS
}

\section{SHALINEE GUPTA ${ }^{1} \&$ MOHIT SHARMA ${ }^{2}$}

${ }^{1}$ Professor \& HOD, Department of Chemical Engineering, Mewar University, Chittorgarh, Rajasthan, India

${ }^{2}$ Student, Mewar University, Chittorgarh, Rajasthan, India

\begin{abstract}
The Common Effluent Treatment Plants (CETP) minimizes the pollution from industrial effluents. This plant monitors the reduction of physical and biochemical parameters such as total suspended solids (TSS), biological oxygen demand (BOD), chemical oxygen demand (COD), dissolved oxygen (DO), heavy metals etc. The Sequential Batch Reactor (SBR), a variation of the ASP, combines all the treatment steps and processes into a single basin. An improved SBR process is Attached Growth Batch Reactor (AGBR) technology that provisions for microbial growth on the settled media/bed to treat the industrial wastewater using enzymes. This technology, when used to treat polluted river water, achieved about $90 \%$ of reduction of wastewater parameters. Hence the same is envisioned for the treatment of industrial effluent. In all the above methods the sludge settlement occurs. It contains biodegradable carbon content which could be used as feed for Biogas Digesters to produce Methane. The present study aims at examining the benefits of combining AGBR and Biogas Digester to implement the 3Rs (Reduce, Recycle, Reuse)
\end{abstract}

KEYWORDS: CETP, SBR, AGBR, Biogas Digester \& Industrial Effluent

Received: Feb 12, 2019; Accepted: Mar 02, 2019; Published: Jul 20, 2019; Paper Id.: IJEEFUSAPR201915

\section{INTRODUCTION}

Water is called the "elixir of life", primarily because it's a survival and sustenance need. Over time, civilizations came into being around water bodies - rivers, ponds, lakes, seas - and human beings began to consume water for drinking, cooking, and cleaning requirements. As water gained its way into all the commercial sectors such as chemical industries, construction sites, food and beverage, textiles and paper mills, animal husbandry, transportation, tourism and recreation, water pollution surfaced. Researches continue to happen around measuring water quality and the effects of polluted water on living beings. The importance of fresh and clean water in sufficient quantities for the existence of life on Earth has always been the primary focus in the minds of environmentalists and scientists. During the course of its use for various purposes, water is subjected to various kinds of treatments and processes involving foreign substances (pollutants), which deteriorates its usage quality. Any contamination in water caused by pollutants that alters the physical and chemical properties of water, making it harmful for human or animal consumption is called water pollution. While it is true that polluted water cannot be used for any purpose whatsoever, there are acceptable water quality standards for every usage determined by standard bodies governing each industry. For instance, the water suited for a manufacturing plant need not be suitable for drinking or agriculture. This is primarily because of the inherent chemical properties of the water sample that are acceptable for the specific purpose. Water polluted with toxic and radioactive wastes or pathogenic bacteria is called contaminated water. Using contaminated water: 
- $\quad$ For drinking, cooking, washing, bathing causes long term health hazards in human beings.

- For irrigation, pollutes the soil and transfers the radio nuclides into the crops.

Organic contaminants in water are highly toxic to human beings and aquatic animals. Widespread organic contaminants include polychlorinated biphenyls (PCBs), detergents and plastics. Polluted water from domestic, agricultural and industrial usage discharge pathogenic pollutants such as bacteria, virus, and protozoa into water bodies. These pathogens are primary causes of contagious diseases in human beings. Some of the Surface water pollutants causing detrimental damage are: Oxygen Demanding Waste, Pathogens, Nutrients, Heavy Metals, Thermal pollutants, Radioactive Pollutants, Synthetic Organic Compounds, Oil and Grease. Wet process industries discharge large volumes of cooling water and water from raw materials, process or both as effluents. These effluents contain a wider range of organic and inorganic substances (acids, alkalis, toxic metals, pesticides, cyanide, dyes, oils, detergents, resins, rubbers, pathogenic bacteria) that are harmful when left untreated into water bodies. This calls for a good and cost-effective waste-water treatment system suitable for economical recycling of the effluents.

\section{EFFLUENT TREATMENT TECHNOLOGIES}

The Common Effluent Treatment Plants (CETP) minimizes the pollution from industrial effluents. This plant monitors the reduction of physical and biochemical parameters such as total suspended solids (TSS), biological oxygen demand (BOD), chemical oxygen demand (COD), dissolved oxygen (DO), heavy metals etc. The Activated Sludge Process (ASP) and Trickling Filter Process (TF) are the classified processes in CETP. The Sequential Batch Reactor (SBR), a variation of the ASP, combines all the treatment steps and processes into a single basin. The process consists of fill, react, settle, decant and idle modes. An improved SBR process is Attached Growth Batch Reactor (AGBR) technology that provisions for microbial growth on the settled media/bed to treat the industrial wastewater using enzymes. This technology, when used to treat polluted river water, achieved about $90 \%$ of reduction of wastewater parameters. Hence the same is envisioned for the treatment of industrial effluent. In all the above methods the sludge settlement occurs. It contains biodegradable carbon content which could be used as feed for Biogas Digesters to produce Methane. The present study aims at examining the benefits of combining AGBR and Biogas Digester to implement the 3Rs (Reduce, Recycle, Reuse).

\section{Common Effluent Treatment Plant (CETP)}

Industrial effluents may be transported to CETP by both tankers and pipelines or either one of them. CETP plays the dual role of both mitigating the pollution and reducing the treatment cost. Advantages of CETP are as follows:

- $\quad$ Reduces cost of pollution abatement for individual factory.

- Provides collective techno-economic solution for treatment of wastewater with fewer personnel and technical setups.

- Resolves space availability issues.

- Avails subsidies provided by the central and state government for plant construction.

- Ensures reduced monitoring cost for the regulators. 


\section{Wastewater Treatment}

Wastewater Treatment involves 4major steps: 1. Preliminary Treatment: It involves removal of large solid particles such as granules, plastics, wood chunks, coarse solids. 2. Primary treatment: It involves process like settling, floatation, flocculation and fine screening. 3. Secondary Treatment: It involves biochemical process, wherein microbes are involved purifying the wastewater. 4. Tertiary Treatment: It involves advanced decontamination process such as UV Treatment, Reverse Osmosis etc.

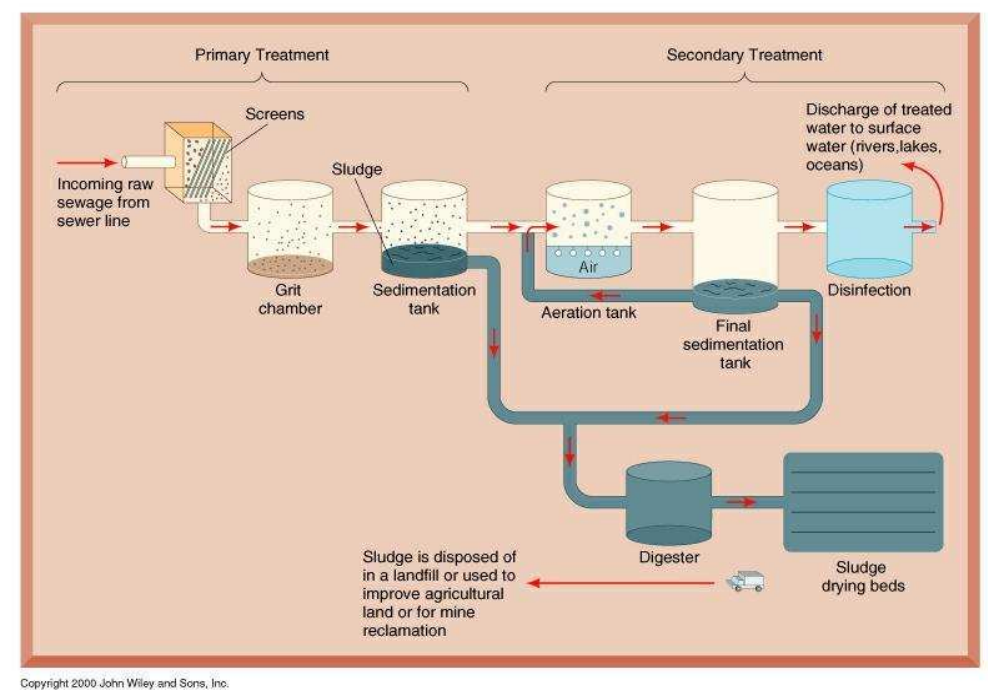

Figure 1: Conventional Wastewater Treatment Process Followed in India

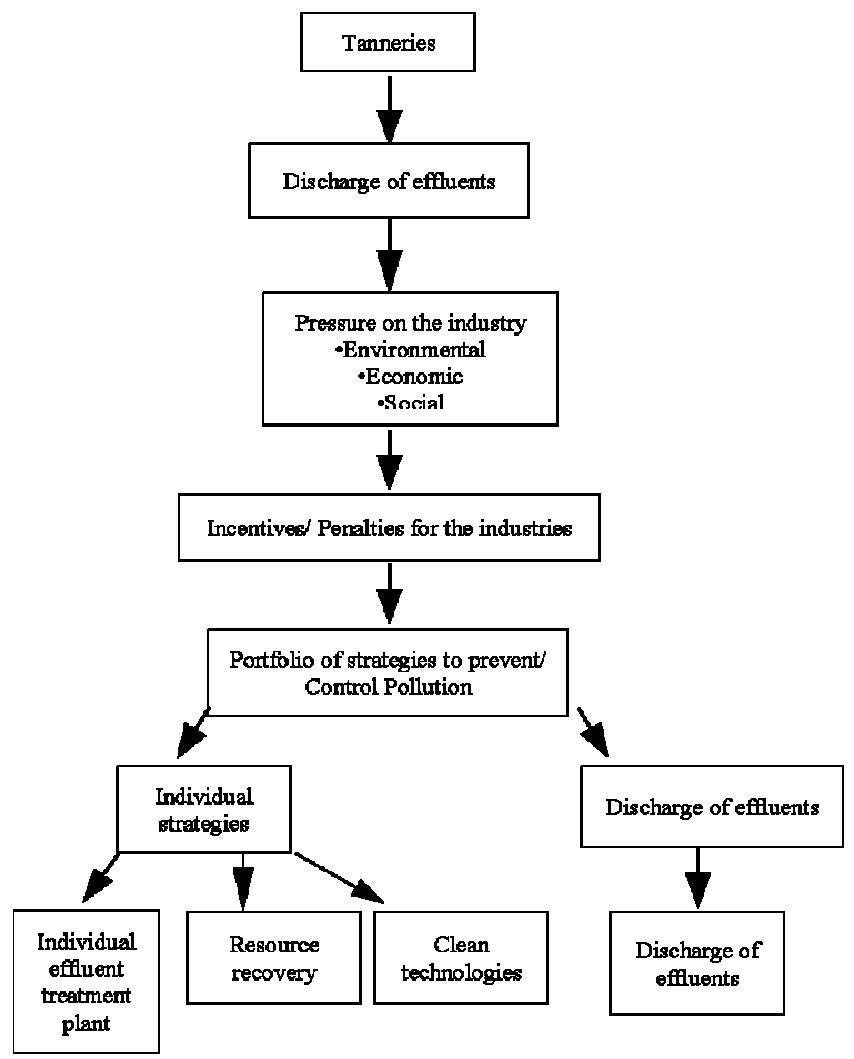

Figure 2: CETP as an Institution 


\section{Sequential Batch Reactor (SBR)}

Activated sludge process and trickling filter system are two of the most often used secondary treatment systems. The SBRs are an effective option in comparison with the conventional activated - sludge system due to their smaller foot print area.

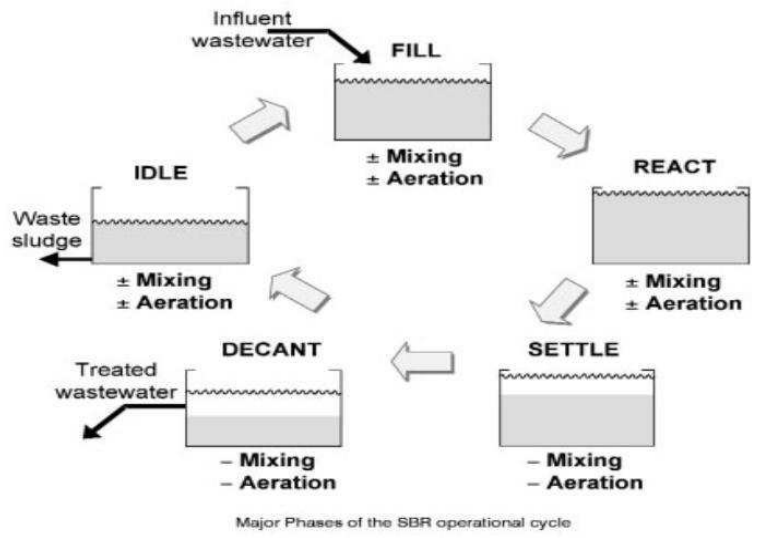

Figure 3: Phases of Sequential Batch Reactor Operational Cycle

The SBR system involves the following process: 1. Fill: Influent is received in the reactor, followed my mixing and aeration that induces biochemical activity. 2. Settle: No inflow, aeration and mixing happen. Activated sludge settles down. 3. Decant: Treated effluent is discharged out. 4. Idle: This process occurs between the decant and the fill phases. The Time changes on the basis of the opening strategy and the influent flow rate.

\section{Attached Growth Batch Reactor (AGBR)}

AGBR has a dual role of both biofilm reactor and SBR, the attached growth batch reactor (AGBR) system has attracted a great deal of attention. Specifically, AGBR systems are capable of covering small areas, showing improved biomass concentration in reactors with corresponding higher specific removal efficiencies, increased process stability toward shock loadings and greater volumetric loads. BOD and COD are more efficiently removed in AGBR systems. During the aeration phase in the AGBR, the presence of an anoxic micro zone in the biofilm could result in simultaneous dénitrification (SND) and nitrification during the aeration phase. Denitrification occurs in the inner layers due to a dissolved oxygen (DO) gradient within the biofilm, when the nitrification occurs on the surface of the biofilm in such cases. While treating low-biodegradable composite chemical wastewater biofilm configured sequencing batch reactor with periodic discontinuous batch mode operation is able to treat larger shock loads than the continuous flow process. To evaluate the treatment of wastewater by AGBR, few experimental studies have been conducted for the best of our knowledge. Polluted river water is used during the start-up period and normal operation to evaluate the performance of the AGBR, in this study the characteristics of the raw domestic sewage are (average value):

Table 1: Average Values of Characteristics of the Raw Wastewater Sewage

\begin{tabular}{|l|c|}
\hline Characteristics & Values \\
\hline $\mathrm{pH}$ & 7.96 \\
\hline temperature & $25^{\circ} \mathrm{C}$ \\
\hline $\mathrm{COD}$ & $972 \mathrm{mg} / \mathrm{L}$ \\
\hline BOD & $220 \mathrm{mg} / \mathrm{L}$ \\
\hline TSS & $52 \mathrm{mg} / \mathrm{L}$ \\
\hline
\end{tabular}


Wastewater is instantaneously poured into the reactor manually and drawn through the outlet after an operation cycle. A small amount of sludge (about $1.5 \mathrm{~g}$ ) is withdrawn from the reactor every day, in order to avoid aging of the sludge due to an extended sludge retention time (SRT). The AGBR is operated at room temperature, according to our previous study, in order to provide enough oxygen for the living of microorganisms. In a single day, two batches of operations are carried out. When a steady state is achieved, decantation was carried out twice a week on a regular basis and treated wastewater was analyzed. This is done until the parameters conformed with respect to Environmental Protection Agency Standards.

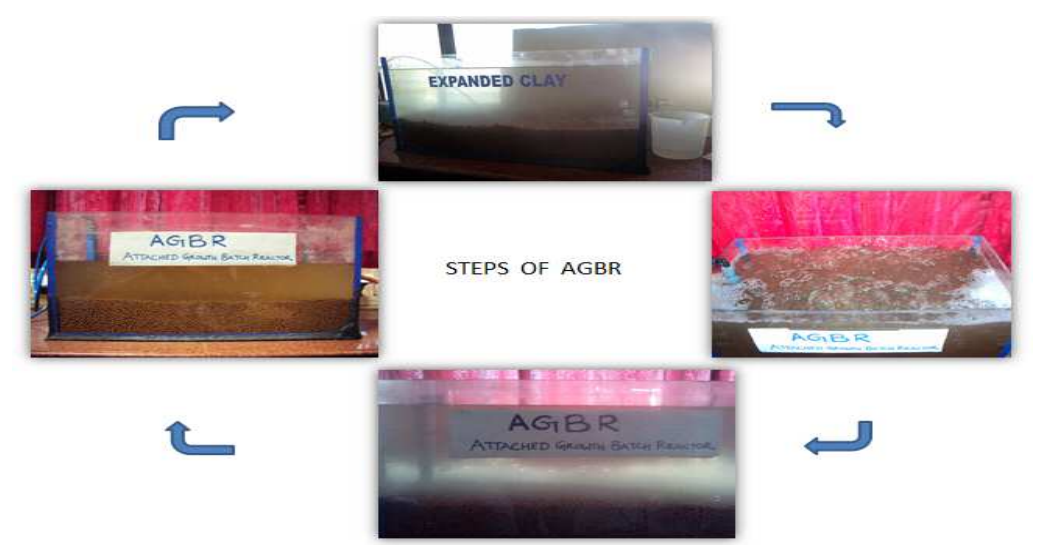

Figure 4: AGBR Treatment Steps

AGBR is carried out with the objective of forming the biofilm during the startup period initially. To obtain steady performance, the AGBR is subsequently operated. Characterizations of the AGBR are analyzed by batch test when a steady state is achieved. The findings are as follows:

Table 2: Polluted River Water Pre \& Post Treated Results

\begin{tabular}{|c|c|c|c|c|c|}
\hline \multirow{2}{*}{ S. No. } & \multirow{2}{*}{ Parameters } & \multirow{2}{*}{ Raw Waste Water } & \multicolumn{3}{|c|}{ Treated Water (Mountainous Rock Material) } \\
\hline & & & $1^{\text {st }}$ Week Part I & $1^{\text {st }}$ Week Part II & $2^{\text {nd }}$ Week \\
\hline 1 & Appearance & Turbid & Slightly turbid & Slightly turbid & Slightly turbid \\
\hline 2 & Color & Blackish & Pale yellowish & Pale yellowish & Pale yellowish \\
\hline 3 & Odour & Characteristic & Odorless & Odorless & Odorless \\
\hline 4 & $\mathrm{pH}$ & 7.96 & 6.84 & 6.83 & 6.82 \\
\hline 5 & TSS (mg/L) & 52 & 10 & 3 & $<2$ \\
\hline 6 & $\begin{array}{c}\text { COD } \\
(\mathrm{mg} / \mathrm{L})\end{array}$ & 972 & 119 & 103 & $<4$ \\
\hline 7 & $\begin{array}{c}\text { BOD } \\
(\mathrm{mg} / \mathrm{L}))\end{array}$ & 220 & 41 & 36 & $<2$ \\
\hline 8 & Phosphate (mg/L) & 6.4 & 1.02 & 0.74 & 0.2 \\
\hline
\end{tabular}

It can be concluded as: 1. The advantages of AGBR include equalization, primary clarification, biological treatment and secondary clarification which can be achieved in a single reactor vessel. Simultaneously the draining and feeding can be done with the mountainous rock material as packing in AGBR. 2. Removing both the BOD and COD from waste water, which results in a good effluent quality can be effectively done by AGBR. 


\section{Biogas Technology}

Biogas is a combination different gases produced by the breakdown of organic matter in the absence of oxygen. Biogas can be produced from raw materials such as agriculture waste, manure, industrial waste, municipal, plant material, sewage, green waste or food waste. It is a renewable energy source. It is produced by the action of methanogens (methane producing bacteria), which digest material inside a closed system, or fermentation of biodegradable materials. Methane produced can be used for cooking, electricity production and can also be stored as CNG (compressed natural gas) for powering motor vehicles.

Table 3: General Composition of Biogas

\begin{tabular}{|c|c|c|}
\hline Compound & $\begin{array}{c}\text { Molecular } \\
\text { Formula }\end{array}$ & $\begin{array}{c}\text { Percentage } \\
\text { Composition }\end{array}$ \\
\hline Methane & $\mathrm{CH} 4$ & $50-75$ \\
\hline Carbon dioxide & $\mathrm{CO} 2$ & $25-50$ \\
\hline Nitrogen & $\mathrm{N} 2$ & $0-10$ \\
\hline Hydrogen & $\mathrm{H} 2$ & $0-1$ \\
\hline Hydrogen sulphide & $\mathrm{H} 2 \mathrm{~S}$ & $0-3$ \\
\hline Oxygen & $\mathrm{O} 2$ & $0-0$ \\
\hline
\end{tabular}

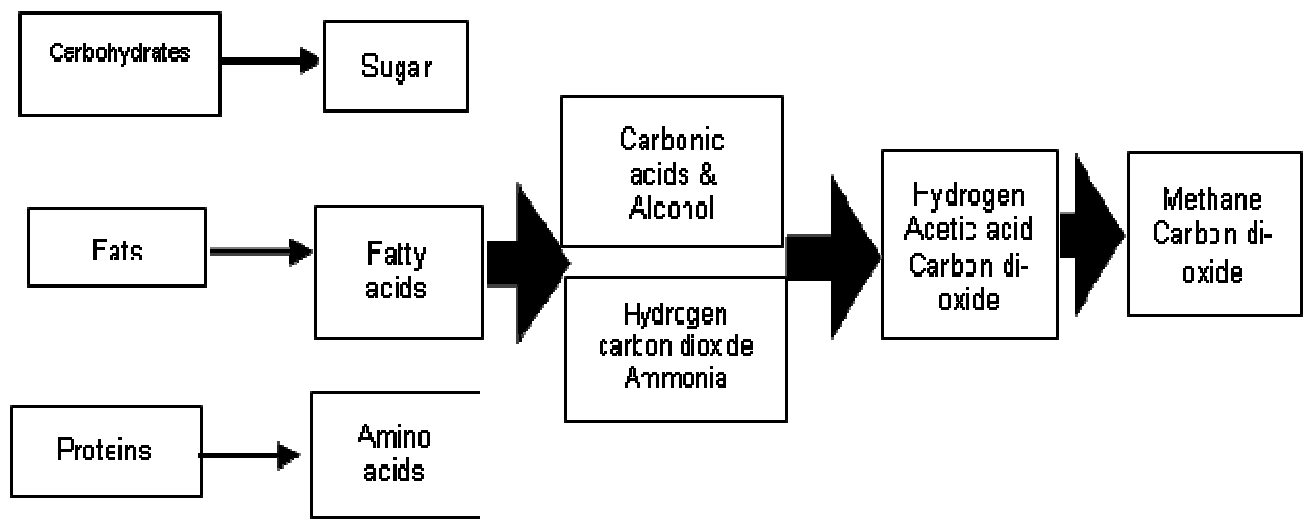

Figure 5: Anaerobic Digestion of Biogas

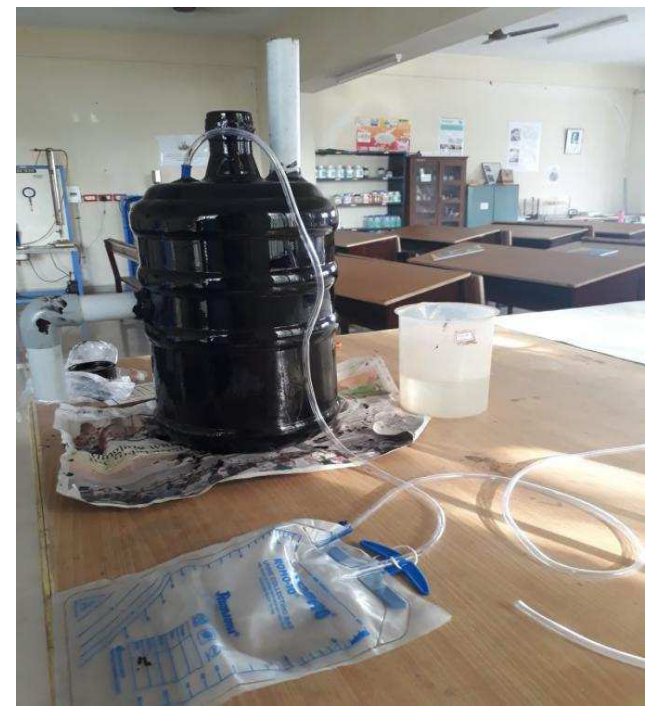

Figure 6: Lab Scale Experimental Setup of Anaerobic Biogas Digester

Bio-slurry, can be used as fertilizer for crop production and aquaculture. 


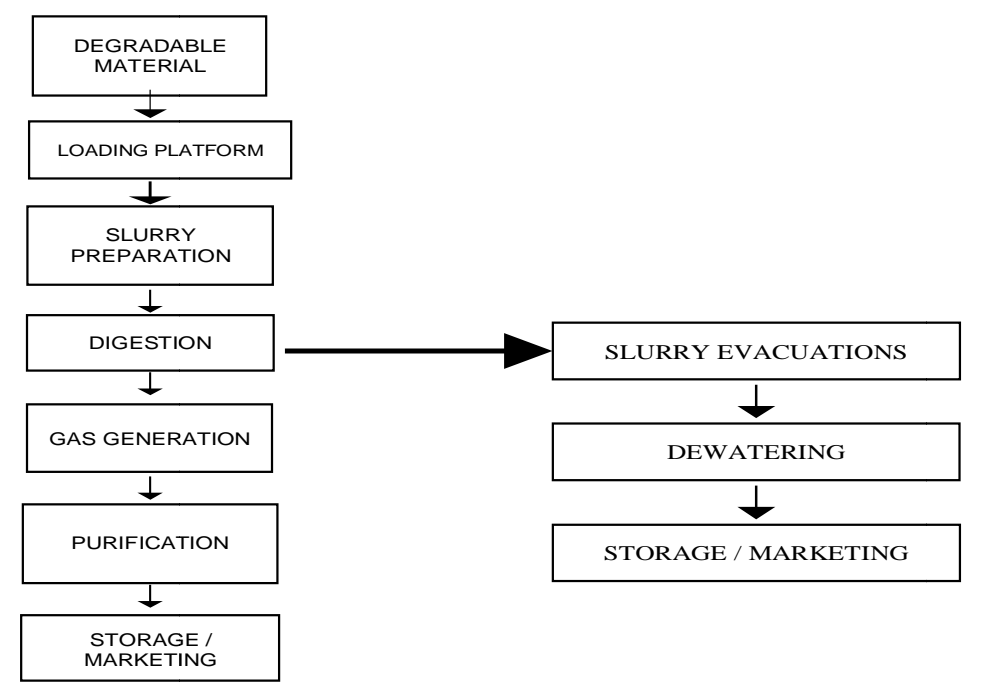

Figure 7: Flow Chart

\section{DATA ANALYSIS AND FINDINGS}

Successful results are obtained for polluted river water using AGBR with greater reduction in wastewater parameters in laboratory scale. And the same is envisaged for industrial effluent treatment and the same needs to be scaled up to industrial level. Anaerobic digestion is a favorable technological solution that degrades a substantial part of the organic matter contained in industrial sludge and solid waste, biogas, helping to alleviate environmental problems.

\section{Table 4: Removal of Efficiency Achieved for Different Physicochemical Parameters of Waste Effluent through Different Methods}

\begin{tabular}{|c|l|c|c|c|}
\hline S. No. & \multicolumn{1}{|c|}{ Parameters } & CETP & SBR & AGBR \\
\hline 1 & BOD Removal & $90 \%$ & $93.5 \%$ & $99.1 \%$ \\
\hline 2 & TSS Removal & $91 \%$ & $91.0 \%$ & $96.2 \%$ \\
\hline 3 & Total Nitrogen Removal & $33 \%$ & $75 \%$ & $70 \%$ \\
\hline 4 & Total Phosphorous Removal & $23 \%$ & $63 \%$ & $96.8 \%$ \\
\hline
\end{tabular}

Maximum Removal efficiency was obtained with AGBR in terms of physicochemical parameters of waste effluent like BOD, TSS and TP. This method is recommended for effective treatment of industrial waste disposal from Industries. Except the nitrogen removal, the BOD, TSS and TP removal efficiency attained by AGBR technology is above 95\%. The above table clearly depicts that AGBR is a superior technology when compared to CETP and SBR.

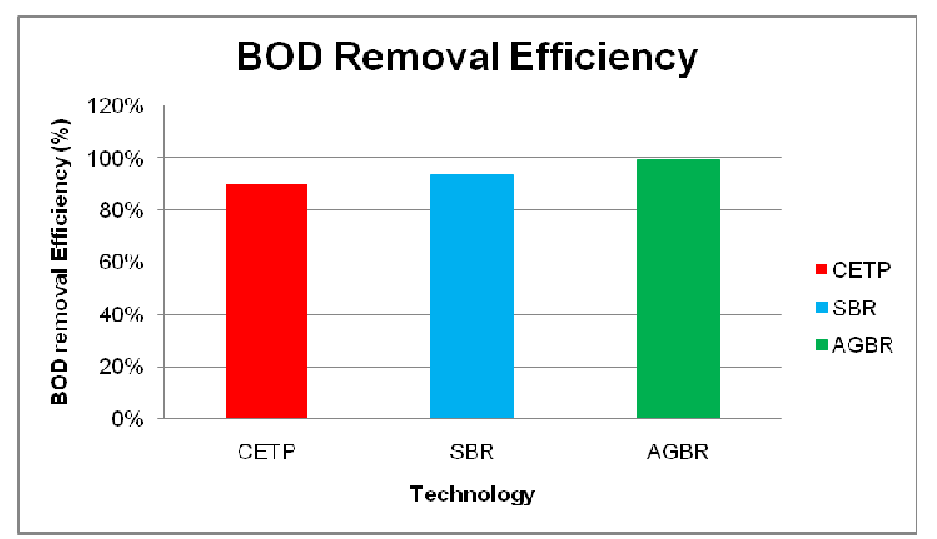

Figure 8: BOD Removal Efficiency Achieved with different Technologies 
Industrial effluent is characterized by one of its measurement called BOD (Biochemical Oxygen Demand). This chart shows, the BOD removal efficiency achieved in waste effluent through different methods. The BOD Removal efficiency achieved through AGBR method is better than the removal efficiency achieved by other methods.

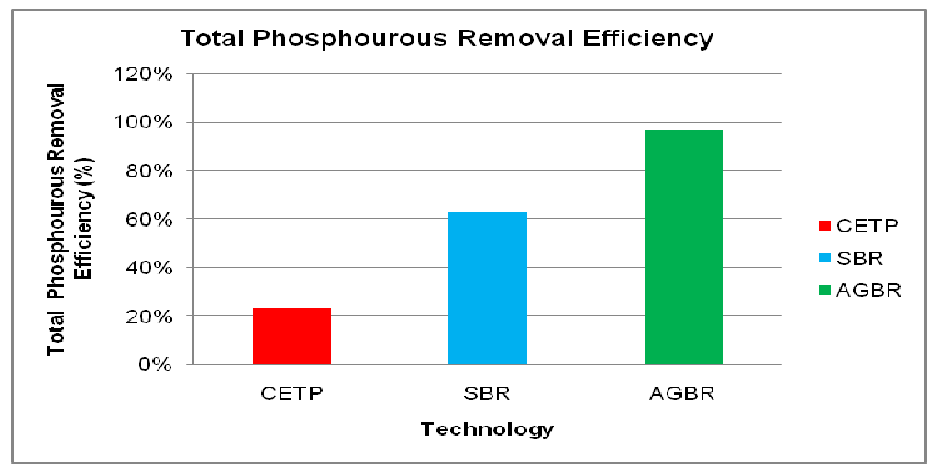

Figure 9: Comparison Chart Showing Total Phosphorus Removal Efficiency Achieved Through Different Methods

Total Phosphorus content in the waste water effluent. This chart shows, the TP removal efficiency achieved in waste effluent through different methods. The TP Removal efficiency achieved through AGBR method is better than the removal efficiency achieved by other methods.

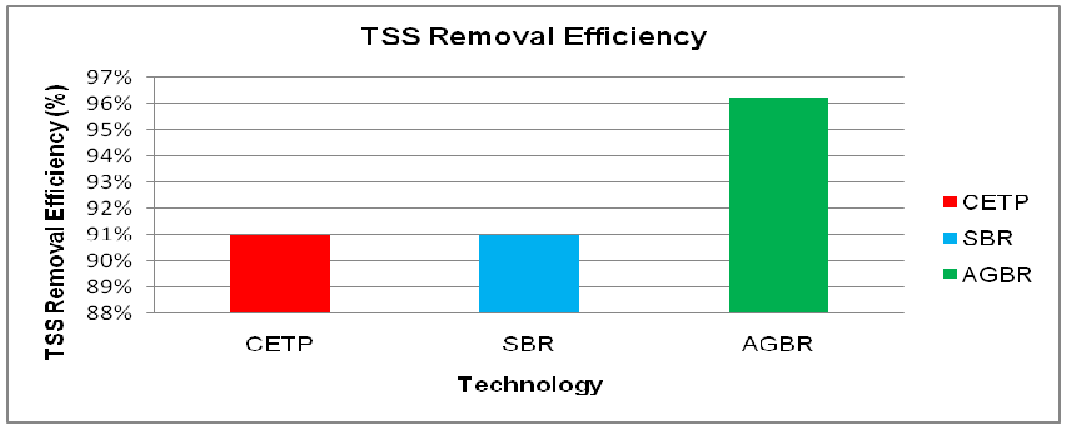

Figure 10: Comparison Chart Showing Total Suspended Solids Removal Efficiency Achieved Through Different Methods

Total Suspended Solids content is a measurement of total solids in the wastewater. This chart shows, the TSS removal efficiency achieved in waste effluent through different methods. The TSS Removal efficiency achieved through AGBR method is better than the removal efficiency achieved by other methods.

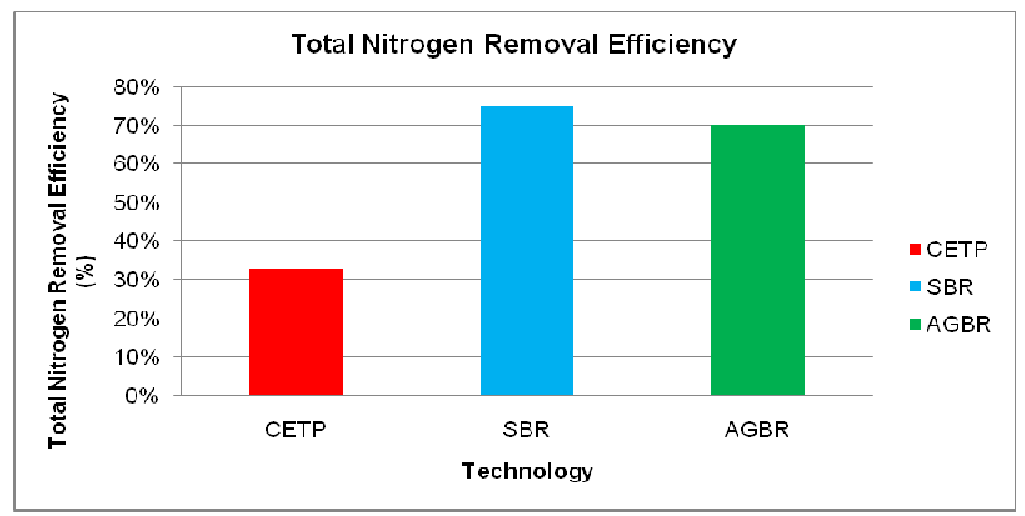

Figure 11: Comparison Chart Showing Total Nitrogen Removal Efficiency Achieved Through Different Methods 
Total Nitrogen is a measure of complete Nitrogen content in the wastewater. This chart shows, the TN removal efficiency achieved in waste effluent through different methods. The TN Removal efficiency achieved through AGBR method is better than the removal efficiency achieved by CETP and slightly lesser than the removal achieved by SBR method.

Table 5: Cost Analysis for Different Methods

\begin{tabular}{|c|l|c|c|c|}
\hline \multirow{2}{*}{ S. No. } & \multicolumn{1}{|c|}{ Parameters } & \multicolumn{3}{|c|}{ Effluent Treatment Methods } \\
\cline { 3 - 5 } & \multicolumn{1}{|c|}{ (For Capacity of 700 KLD) } & 235 & 300 & 310 \\
\hline 1 & Capital Costs (in Lakhs) & 3.25 & 3.75 & 0.25 \\
\hline 2 & Operating \& Maintenance Costs (in Lakhs per month) \\
\hline
\end{tabular}

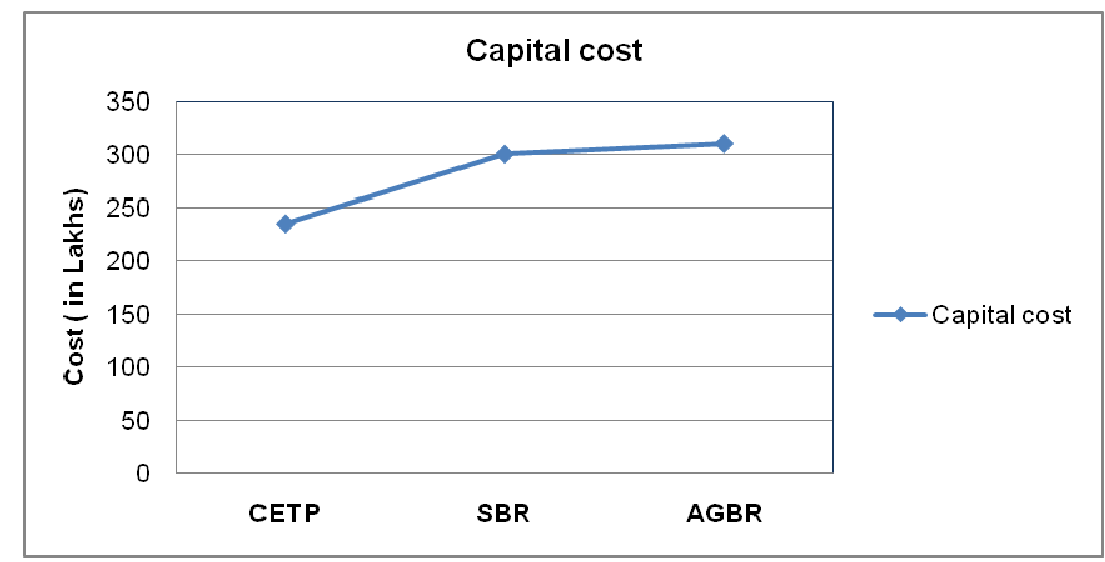

Figure 12: Comparison Chart showing Capital Cost Involved in Different Methods

* Note: The Costs of the AGBR Technology is an estimated cost, since, the technology is still in Lab Scale and needs to be implemented in commercial scale.

Costs Headers of Effluent Treatment equipment's include the Capital costs and Operating and Maintenance costs. The Capital cost includes the Civil construction and Tanks, Electro-mechanical components: Pumps, Blowers etc. The above chart shows the Capital cost for different technologies. The Capital cost of CETP is cheaper and the costs of other two technologies are almost similar.

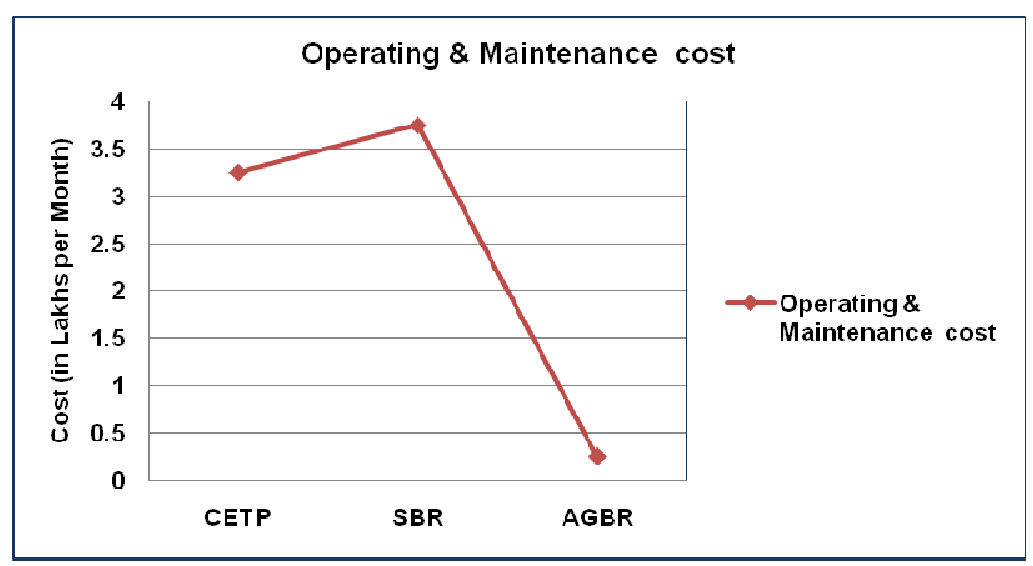

Figure 13: Comparison Chart Showing Operating \& Maintenance Cost Involved in Different Methods

The Operating and Maintenance cost includes Labour, Electricity, Consumables, Minor maintenance etc. The above chart shows the Operating and maintenance cost for different technologies. The Operating and Maintenance costs 
for AGBR is lesser than the other two technologies, which will be beneficial on a longer run.

Based on the Research and Graphical analysis carried out. The Proposed AGBR technology is more effective in reducing the wastewater parameters of industrial effluent compared to other technologies available in market. Hence, AGBR is envisaged as appropriate method for effective control of the effluent waste generated from the tanneries.

\section{CONCLUSIONS}

Based on the study undertaken the following process is recommended to achieve the dual process of zero waste discharge and waste to energy production, for the effluent emanating from the tanning environment.

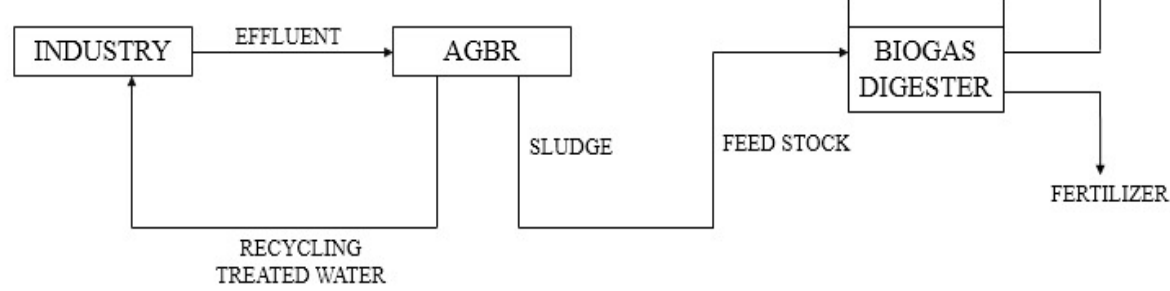

Figure 14: Liquid \& Solid Waste Management Process Using Two Stage AGBR\& Anaerobic Digester

This study highlights the detrimental effect of untreated industrial effluent discharge, the mandatory policies of the pollution control board to set up common effluent treatment plants, the advantage of AGBR over the conventional SBR set- up and the importance of biogas digester in biodegrading the sludge produced during industrial effluent treatment. Based on the combination of AGBR and Biogas Technology, the industrial effluent is treated. The treated water is recycled for processing purpose. The sludge produced from the effluent treatment is now then taken as feed for the biogas digester for methane production, which is a biofuel. The slurry obtained from the digester is used as fertilizer. Hence, we achieve the dual process of zero waste discharge and waste to energy production.

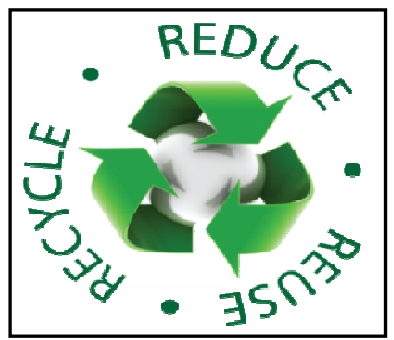

Figure 15: 3 R's - Reduce, Recycle, Reuse

\section{REFERENCES}

1. Aloka Debi. Environmental Science \& Engineering.

2. M. Manivasakam Industrial Effluents- Origin, Characteristics, Effects, Analysis \& Treatment

3. SC Bhatia. Pollution Control in Chemical and Allied Industry

4. Pollution Management In Leather Tanning: The Indianexperience

5. Alebel Abebe Belay. Journal of Environmental Protection, 2010, 1, 53-58. Impacts of Chromium from Tannery Effluent and 
Evaluation of Alternative Treatment Options.

6. Chromium-bearing waste lying on open land within Tamil Nadu Chromates and Chemicals Limited at SIPCOT Industrial Complex, polluting groundwater in a 30-km radius. https://www.thehindu.com/news/national/the-groundwater-beneath-theirfeet/article17321183.ece (accessed on October 3, 2018.)

7. Sequencing Batch Reactor Design and Operational Considerations. Prepared by the New England Interstate Water Pollution Control Commission. September 2005.

8. International Journal of Information Research and Review, October 2015. Wastewater treatment using attached growth batch reactor (agbr) technology.

9. Energy Recovering from Tanneries By Biogas Production. Mădălina Mavrodin, Cătălina Raluca Mocanu, Gheorghe Lăzăroiu, Dana Andreya, Bondrea, Bogdan Niculescu, Roberto Cipollon. 4th International Conference on Thermal Equipment, Renewable Energy and Rural Development.

10. C S Rao, Environmental Pollution Control Engineering

11. A. H. Mahvi, Sequencing Batch Reactor: A promising Technology in Wastewater Treatment, Environ Health Sci Engg. 2008

12. Munyoro, G., Shadaya, G. K., \& Masiyiwa, R. The effects of land Reform on the Agriculture Retailing Industrial Sector in Zimbabwe: a case study of farm and city centre.

13. Vijay Samuel et al., Biochemical and Toxicological Studies on Polluted Water using AGBR, International Journal of Engineering \& Technology.

14. Environmental Biotechnology (Industrial Pollution Management), S. N. Jognand. 
